\title{
Influence of Seedling Age on the Susceptibility of Tomato Plants to Ralstonia solanacearum during Protray Screening and at Transplanting
}

\author{
Pious Thomas*, Reshmi Upreti \\ Division of Biotechnology, Indian Institute of Horticultural Research, Bangalore, India \\ Email: ${ }^{*}$ pioust@gmail.com, ${ }^{*}$ pioust@iihr.ernet.in
}

Received 30 March 2014; revised 28 April 2014; accepted 10 May 2014

Copyright (C) 2014 by authors and Scientific Research Publishing Inc.

This work is licensed under the Creative Commons Attribution International License (CC BY).

http://creativecommons.org/licenses/by/4.0/

c) (i)

\section{Abstract}

The study was undertaken to assess whether seedling age played any role in governing the vulnerability of tomato to the bacterial wilt pathogen, Ralstonia solanacearum, based on the preliminary observations that the extent of mortality during seedling-stage screening was relatively less in older seedlings. Employing the virulent strain 'NH-Av01' isolated from tomato, 2-, 3-, 4- or 5-weekold seedlings of susceptible 'Arka Vikas' raised in organic cocopeat in 98 cavity protrays were inoculated with the pathogen through root-injury inoculation approach. Disease symptoms appeared earlier and with more severity in 2-week-old seedlings followed by 3-, 4- and 5-week-old saplings recording $74 \%, 68 \%, 63 \%$ and $49 \%$ mortality, respectively, after four weeks of inoculation suggesting that older the seedlings, less the susceptibility to the pathogen. The growth characteristics of seedlings (shoot height, shoot and root weights) showed a significant increase with seedling age (0.21, 0.54, 1.14 and 2.09 gross weight/seedling at $2,3,4$ and 5 weeks, respectively) indicating healthier saplings with delay in inoculation time. In subsequent trials, seedlings of $3,4,5$ or 6 weeks were transplanted to field-sick soil in protrays or in pots with monitoring for 1 - 4 months which indicated a significant reduction in disease incidence and severity with increase in seedling age. The observations suggested that seedling age should be considered as a major factor influencing the susceptibility of tomato seedlings to $R$. solanacearum with the chances of variations in the extent of disease incidence or inconsistent results during seedling-stage screening and the possibility of escapes with older seedlings. Two-week seedlings formed the best when the aim is to induce maximum disease incidence, while transplanting at 5 - 6 weeks stage appeared the best when the objective is minimal disease incidence or formulating disease management strategies.

\footnotetext{
${ }^{*}$ Corresponding author.
} 


\section{Keywords}

\section{Bacterial Wilt, Disease Resistance, Screening Methodology, Seedling Vigor, Solanum lycopersicum, Tomato Breeding}

\section{Introduction}

Wilt caused by the bacterial pathogen, Ralstonia solanacearum is a serious limiting factor affecting the cultivation of tomato world over [1] [2]. The pathogen has a wide host range and is able to survive in soil, crop debris or weed hosts making the disease control a cumbersome process except for the use of disease resistant varieties [1]-[3]. It is essential to evolve disease management practices to facilitate the growing of wilt-susceptible otherwise superior genotypes. Practices like crop rotation, use of antagonistic microorganisms and soil amelioration are adopted towards this objective [1] [3]-[6].

Ralstonia solanacearum colonizes the host in the vascular elements interfering with the movement of water and nutrients [1]-[3]. The primary route of infection is roots which are injured at transplanting, during cultural operations or through the action of nematodes and other pests [1] [4]. Tomato being essentially a transplanted crop, injury to roots at field planting is often inevitable. With the practice of growing the seedlings in organic planting medium in protrays, it has been possible to plant them in the field with the intact ball of cocopeat thereby minimizing the chances of root injury.

Evaluating different seedling-stage inoculation methods for screening tomato (Solanum lycopersicum) genotypes against $R$. solanacearum, we have observed that direct delivery of inoculum to the shoot tissue interfered with the resistance characteristic of proven resistant genotypes [7]. Root-injury and inoculation on two-week-old seedlings appeared the best approach to facilitate the discrimination between known resistant and susceptible genotypes with the knocking down of most of the susceptible plants before field planting. While undertaking screening trials with the root-injury inoculation approach, the disease incidence appeared to be less than the normally expected levels in some of the trials. A perusal of the data from such trials suggested that the disease incidence was possibly modified by the age of the seedlings used in the screening program. The present investigations were undertaken with a view to assess if the seedling age in tomato at the time of challenge in the nursery or the point of exposure to the pathogen in the field has any influence on the extent to disease incidence or susceptibility to $R$. solanacearum.

\section{Materials and Methods}

\subsection{Culture of Pathogen and Inoculation Method}

Ralstonia solanacearum strain 'NH-Av01' (NCBI Acc. no. KJ412034) isolated from the bacterial ooze of a wilted 'Arka Vikas' plant was used as the pathogen. The culture was stored as glycerol stocks at $-80^{\circ} \mathrm{C}$ and revived on Kelman [8] medium. The media constituents, namely, bacteriological peptone (RM 001-500G), casein enzyme hydrolysate-Type II (CR 028-500G), dextrose (RM 077-500G) and bacteriological agar (RM 006-500G) were sourced from Hi Media BioSciences Mumbai, and 2,3,5-triphenyl tetrazolium chloride (TTC) from Sigma-Aldrich, St. Louis, MO, USA. These descriptions are given based on the observations that the colony characteristics and virulence of the pathogen could be altered with the source of media constituents (Thomas and Upreti, unpublished results). The TTC stock $\left(100 \mathrm{mg} \cdot \mathrm{ml}^{-1}\right)$ after filter-sterilization was stored as aliquots of 1.25 $\mathrm{ml}$ at $-20^{\circ} \mathrm{C}$, and incorporated to $250 \mathrm{ml}$ of autoclaved and cooled medium just before pouring. The $-80^{\circ} \mathrm{C}$ glycerol stock was spotted on Kelman-TTC (KM-TTC) medium and used for the preparation of inoculum after 2 days at $30^{\circ} \mathrm{C}$ which showed fluidy white colonies with red center [8].

\subsection{Plant Material}

Tomato cv. Arka Vikas released from this Institute was employed as the standard susceptible genotype [7]. The seedlings were raised in 98 cavity portrays in pasteurized cocopeat, a common coconut husk-based organic growing medium for raising vegetable seedlings (M/s Varsha Enterprises, Bangalore, India) as described else- 
where [7]. All the experiments were conducted under glass house conditions.

\subsection{Inoculation of Seedlings of Different Age Groups}

Seedlings of 2, 3, 4, and 5 weeks from the date of sowing in protrays were employed for root-injury inoculation as per Thomas et al. [7]. Briefly, the roots were injured by inserting a No. 22 scalpel blade on one side of the seedlings about $1 \mathrm{~cm}$ away from the base followed by drenching with $2 \mathrm{ml}$ of $0.1 \mathrm{OD}\left(\mathrm{A}_{600 \mathrm{~nm}}\right)$ inoculum prepared in autoclaved distilled water. Seedlings of different age groups were challenged with the same lot of inoculum. This warranted seed sowing staggered over 4 weeks with separate protrays for different treatments. There were seven replications with 14 seedlings per replication. The control set included seedlings grown under identical conditions without applying the inoculum. The extent of disease incidence was assessed weekly for four weeks based on the extent of irreversible witling or mortality (\%). The experiment was repeated twice. Another experiment was set up under identical conditions where the seedlings were given simple cocopeat soaking inoculation without imparting injury to the roots [7].

\subsection{Assessment of Seedling Growth}

The growth characteristics of seedlings belonging to 2-, 3-, 4- or 5-week age groups were assessed from a set of seedlings grown under identical conditions. In this trial, the seeds were sown at the same time with the sampling staggered over 4 weeks. Shoot height, root length and fresh weight of shoot, root and whole seedlings were recorded after destructive sampling employing seven replications with 14 seedlings constituting one replication.

\subsection{Transplanting to Sick Soil in Protrays}

The seedlings normally come in contact with the pathogen at the time of field transplanting. With the protraygrown seedlings, this normally occurs by 3 - 4 weeks. Based on the observations that the disease incidence was relatively less in older seedlings in protray screenings, the transplanting of seedlings of different age groups to the sick-soil was envisaged. Seedlings of two weeks were not included in this trial as they are too delicate for transplanting. On the other hand, 6-week-old seedlings were considered to confirm the age effect. The seedlings were raised in 98 cavity protrays (without pathogen challenge) with staggered sowing and 3-, 4-, 5- or 6-weekold seedlings with the intact ball of cocopeat were transplanted to 50-cavity protrays providing a thin layer of pathogen-sick soil at the bottom and filling the sides with the same. The sick-soil was prepared by mixing the soil collected from the rhizosphere of wilted tomato plants with sand and cocopeat in equal proportions $(\mathrm{v} / \mathrm{v})$ and further fortification with $100 \mathrm{ml}$ of $0.1 \mathrm{OD}$ bacterial inoculum per $\mathrm{Kg}$ of mixture. The inoculum level in the transplanting medium was assessed on SMSA medium [9] through the spotting-and-tilt-spreading (SATS) approach [10] registering a CFU of $10^{6}$ to $10^{7} \mathrm{~g}^{-1}$. The extent of seedling survival in different age groups was monitored at fortnightly intervals for 6 weeks.

\subsection{Extended Monitoring in Pot Culture}

Seedlings from the age groups of 3, 4, 5 and 6 weeks were transplanted to 6-inch black plastic pots filled with the pathogen sick-soil as above. There were five replications with five plants per replication. The plants were monitored for three months under glasshouse conditions for disease incidence.

In a subsequent trial, 3-week-old seedlings were transplanted to sick soil in pots and once these plants were knocked down by 3 weeks, the pots were re-planted with seedlings of the same batch which by this time have turned 6 weeks. There were 30 plants altogether and the extent of disease incidence/mortality was recorded for 3 months. A subsequent trial had 3-, 4-, 5- or 6-week-old seedlings transplanted to 10-inch earthen pots containing sick-soil (10 per treatment). The plants were monitored till flowering and fruiting for 4 months.

\subsection{Statistical Analysis}

Data were analyzed for single factor ANOVA employing the data analysis package of Microsoft Excel-2007 as earlier [7]. The response of different age groups was assessed based on the extent of mortality on the scale: $\leq 10 \%$, high resistance (HR); $10 \%-40 \%$, moderate resistance (MR); $>40 \%$ to $70 \%$, moderate susceptibility (MS) and $>70 \%$, high susceptibility (HS) [7]. 


\section{Results}

\subsection{Response of Seedlings of Different Age Groups at Protray Screening}

Comparing the 2 - 5-week-old seedlings of Arka Vikas through root-injury inoculation, the younger the seedling, the more was the susceptibility to the pathogen (Figure 1). Disease symptoms appeared earlier and with more severity in 2-week-old seedlings followed by 3-, 4- and 5-week-old saplings registering 65\%, 38\%, 35\% and 19\% mortality, respectively, after two weeks of challenge. By 4 weeks, the extent of mortality in the first three age groups appeared almost similar, but it was relatively less in 5-week-old seedlings with the maximum plant stand (74\%, 68\%, 63\% and 49\% mortality, respectively). Thus, the same genotype under identical conditions was rated as HS (3-week-old) or MS (4-, 5- and 6-week-old) based on the seedling age. The two repeat trials with root-injury inoculation endorsed the observation that younger seedlings were more susceptible to the pathogen while the older seedlings displayed more tolerance (Data not shown). The trial adopting mere cocopeat drenching inoculation without root injury showed similar results on the intensity of disease incidence in relation to the seedling age but the overall disease incidence was low compared with root-injury-inoculation classifying them as HR (4and 5-week-old) or MR (2- and 3-week-old) depending on seedling age and inoculation method (Figure 2). The results altogether indicated that seedling age in protrays was a crucial factor governing the susceptibility of tomato seedlings to the pathogen. Two weeks seedlings formed the best stage when the aim was to induce maximum disease incidence while 4 - 5 weeks age appeared the best if the objective was minimal disease incidence.

\subsection{Growth Characteristics of Seedlings of Different Age Groups}

With the advancement in the age of seedling, there was a significant increase in all the growth characteristics such as shoot height, shoot weight, root length, root weight and overall seedling weight (Table 1). Ralstonia being a root-invading pathogen, root growth characteristic was considered to be of more significance. Between 2 and 3-week-old seedlings, there was a fourfold increase in root weight, threefold rise between 3 - 4 weeks and a two-fold increase during 4 - 5 weeks stage with the root weights of 14, 59, 146 and $273 \mathrm{mg}$ for 2-, 3-, 4- and 5week-old seedlings, respectively. The gross seedling weight also showed a significant increase with seedling age (213, 535, 1136 and $2087 \mathrm{mg}$ at 2, 3, 4 and 5 weeks, respectively) indicating healthier saplings with delay in inoculation time.

\subsection{Seedling Survival after Transplanting to Sick Soil in Protrays}

Three to 3.5 weeks old protray seedlings in cocopeat are generally employed for transplanting to the field in

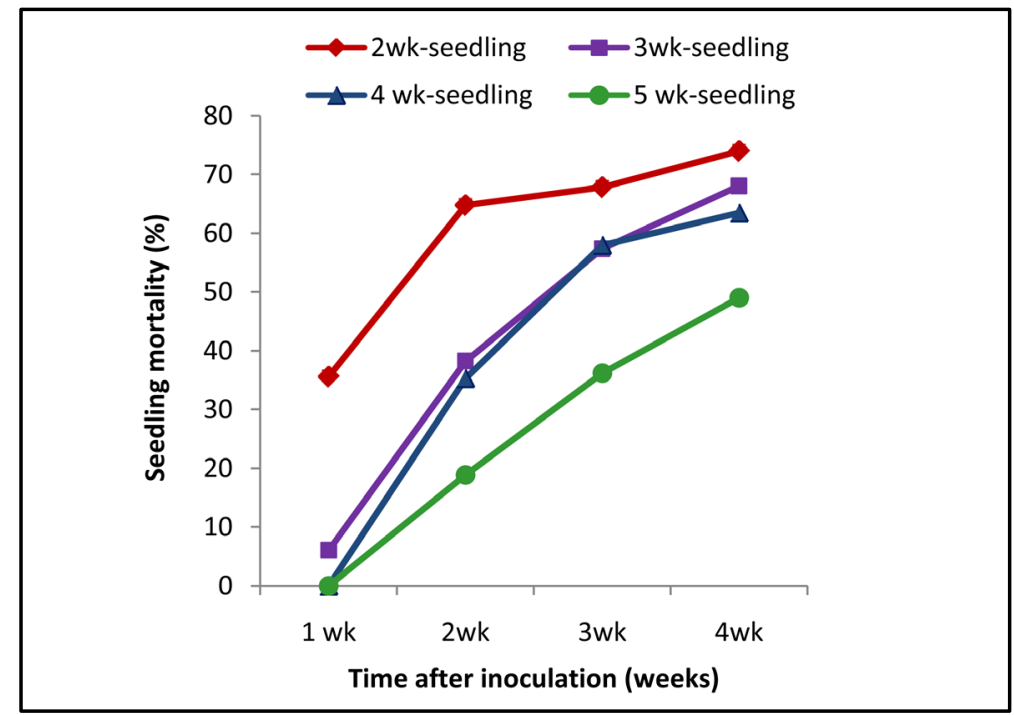

Figure 1. Extent of mortality (\%) following inoculation of tomato cv. Arka Vikas seedlings with Ralstonia solanacearum 2, 3, 4 or 5 weeks after sowing through root-injury inoculation. 


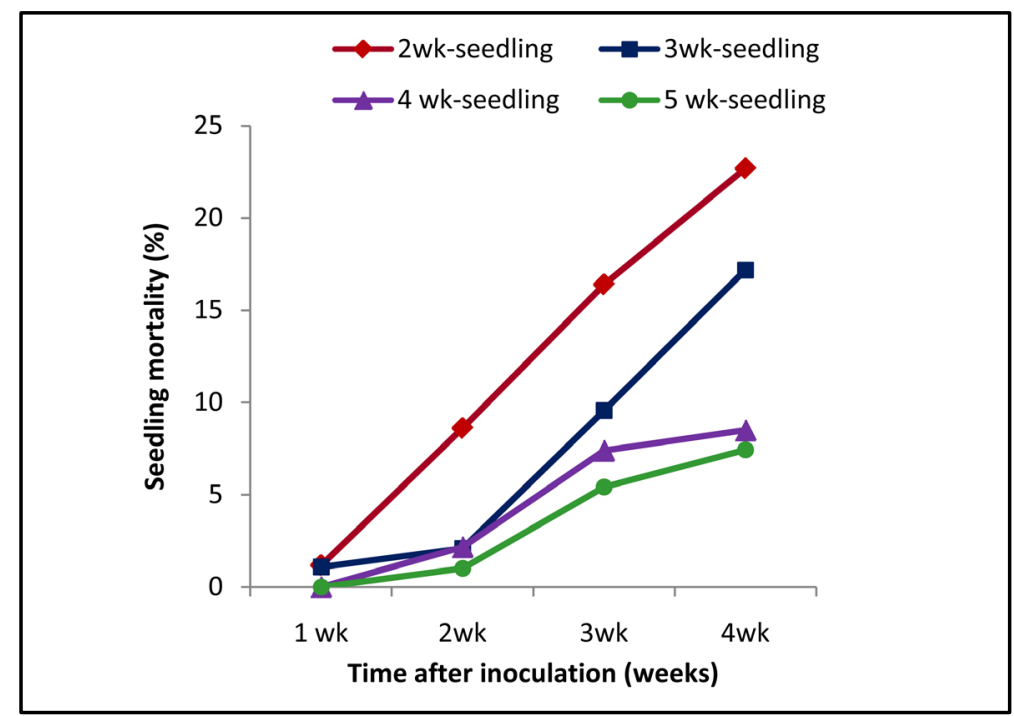

Figure 2. Extent of mortality (\%) following inoculation of tomato cv. ArkaVikas seedlings with Ralstonia solanacearum 2, 3, 4 or 5 weeks after sowing through simple cocopeat drenching inoculation.

Table 1. Growth characteristics of protray grown seedlings of tomato cv. Arka Vikas belonging to different age groups.

\begin{tabular}{cccccc}
\hline Seedling age & Seedling height $(\mathrm{cm})$ & Root length $(\mathrm{cm})$ & Shoot weight $(\mathrm{mg})$ & Root weight $(\mathrm{mg})$ & Total seedling weight (mg) \\
\hline 2 weeks & $8.0^{\mathrm{a}}$ & $3.24^{\mathrm{a}}$ & $199.3^{\mathrm{a}}$ & $14.3^{\mathrm{a}}$ & $213.6^{\mathrm{a}}$ \\
3 weeks & $14.2^{\mathrm{b}}$ & $5.44^{\mathrm{b}}$ & $471.6^{\mathrm{a}}$ & $59.0^{\mathrm{a}}$ & $534.5^{\mathrm{a}}$ \\
4 weeks & $18.0^{\mathrm{c}}$ & $8.2^{\mathrm{c}}$ & $990.7^{\mathrm{b}}$ & $145.8^{\mathrm{b}}$ & $1136.4^{\mathrm{b}}$ \\
5 weeks & $22.7^{\mathrm{d}}$ & $9.21^{\mathrm{c}}$ & $1814.1^{\mathrm{c}}$ & $273.1^{\mathrm{c}}$ & $2087.2^{\mathrm{c}}$ \\
\hline Significance & $* *$ & ${ }^{* *}$ & $*^{* *}$ & & $* *$ \\
CD & 2.22 & 1.28 & 301.1 & 58.1 & 356.2 \\
\hline
\end{tabular}

${ }^{* *}$ Significant at $P=0.01$; CD, critical difference at $P=0.05$; Values followed by the same letter in a column are not significantly different.

the normal course and it is not usual to keep them beyond four weeks. However, transplanting the 3 - 6 weeks old seedlings to the sick soil in the protrays indicated that 3- and 4-week-old seedlings were more susceptible to the pathogen registering $\geq 80 \%$ mortality within one week of transplanting (Table 2). Transplanting at 5 - 6 weeks stage delayed the appearance of disease symptoms, showed less disease incidence during the 1 - 3 weeks period after transplanting and registered relatively low mortality by 4 weeks. A repeat trial, where 3 - 6 week-old seedlings were monitored for 6 weeks after their transplanting to sick soil in lager-protrays (32 cavity) endorsed that seedling age was a crucial factor where 3- and 4-week-old seedlings proved highly vulnerable followed by 5- and 6-week-old saplings (Figure 3).

\subsection{Pot Culture Experiments}

In the initial pot culture trial in 6-inch pots, the seedlings could be monitored till the flowering stage. The 3 weeks old seedlings showed high mortality within 2 - 4 weeks of transplanting whereas the $4-6$ weeks old seedlings displayed relatively less disease incidence by 4 weeks after planting (Table 3). After 10 weeks, 20\% saplings of 6 weeks and 16\% saplings from the 5 weeks transplanting showed survival while the respective figures for 4 and 3 weeks old seedlings were only $8 \%$ and $4 \%$. The observations thus indicated that seedling age at transplanting to sick soil had a clear effect on the hosts' vulnerability to the pathogen.

In a confirmation trial, 3-week-old seedlings were transplanted to sick-soil in pots where all the seedlings showed mortality within $2-3$ weeks. The seedlings from the same protray (6 weeks old by now) which were 
Table 2. Description of condition of tomato seedlings of 3, 4, 5 or 6 weeks at transplanting and the extent of mortality (\%) following the transplanting to the Ralstonia-sick soil in protrays.

\begin{tabular}{|c|c|c|c|c|c|}
\hline \multirow{2}{*}{$\begin{array}{l}\text { Seedling age at } \\
\text { transplanting }^{\dagger}\end{array}$} & \multirow{2}{*}{ Seedling condition at transplanting } & \multicolumn{4}{|c|}{ Extent of seedling mortality (\%) 1 to 4 weeks after the transplanting } \\
\hline & & 1 week & 2 weeks & 3 weeks & 4 weeks \\
\hline 3 weeks & Relatively small; not quite ready for transplanting & $94.4^{\mathrm{a}}$ & $100^{\mathrm{a}}$ & $100^{\mathrm{a}}$ & $100^{\mathrm{a}}$ \\
\hline 4 weeks & Apparently healthy and ready for transplanting & $78.5^{\mathrm{b}}$ & $85.7^{\mathrm{a}}$ & $85.7^{\mathrm{a}}$ & $92.8^{\mathrm{a}}$ \\
\hline 5 weeks & Overgrown, but healthy and green & $16^{\mathrm{c}}$ & $56^{\mathrm{b}}$ & $94.4^{\mathrm{a}}$ & $100^{\mathrm{a}}$ \\
\hline \multirow[t]{2}{*}{6 weeks } & Pot bound and pigmented; drying of lower leaves & $0^{\mathrm{d}}$ & $34.1^{\mathrm{c}}$ & $56.1^{\mathrm{b}}$ & $74.1^{\mathrm{b}}$ \\
\hline & Significance & ** & $* *$ & ** & $*$ \\
\hline
\end{tabular}
$*{ }^{* *}$ Significant at $P=0.05$ and 0.01 , respectively; Values followed by the same letter in a column are not significantly different. ${ }^{\dagger}$ seedlings trans-
planted to sick soil with the ball of cocopeat.

Table 3. The extent of mortality recorded following transplanting of 3 - 6 weeks old seedlings of tomato cv. Arka Vikas to Ralstonia sick soil in 6" plastic pots.

\begin{tabular}{|c|c|c|c|}
\hline \multirow{2}{*}{ Seedling age at transplanting ${ }^{\dagger}$} & \multicolumn{3}{|c|}{ Extent of seedling mortality (\%) recorded at different time spans after transplanting } \\
\hline & 2 weeks & 4 weeks & 10 weeks \\
\hline 3 weeks & $36^{\mathrm{a}}$ & $76^{\mathrm{a}}$ & $96^{\mathrm{a}}$ \\
\hline 4 weeks & $16^{\mathrm{b}}$ & $36^{\mathrm{b}}$ & $92^{\mathrm{a}}$ \\
\hline 5 weeks & $8^{\mathrm{b}}$ & $28^{\mathrm{b}}$ & $84^{\mathrm{a}}$ \\
\hline 6 weeks & $4^{\mathrm{b}}$ & $24^{\mathrm{b}}$ & $80^{\mathrm{a}}$ \\
\hline Significance & ** & ** & NS \\
\hline
\end{tabular}

${ }^{\dagger}$ Seedlings transplanted to sick soil with the ball of cocopeat; Values followed by the same letter in a column are not significantly different. ${ }^{* *}$ Significant at $P=0.01$, NS not significant.

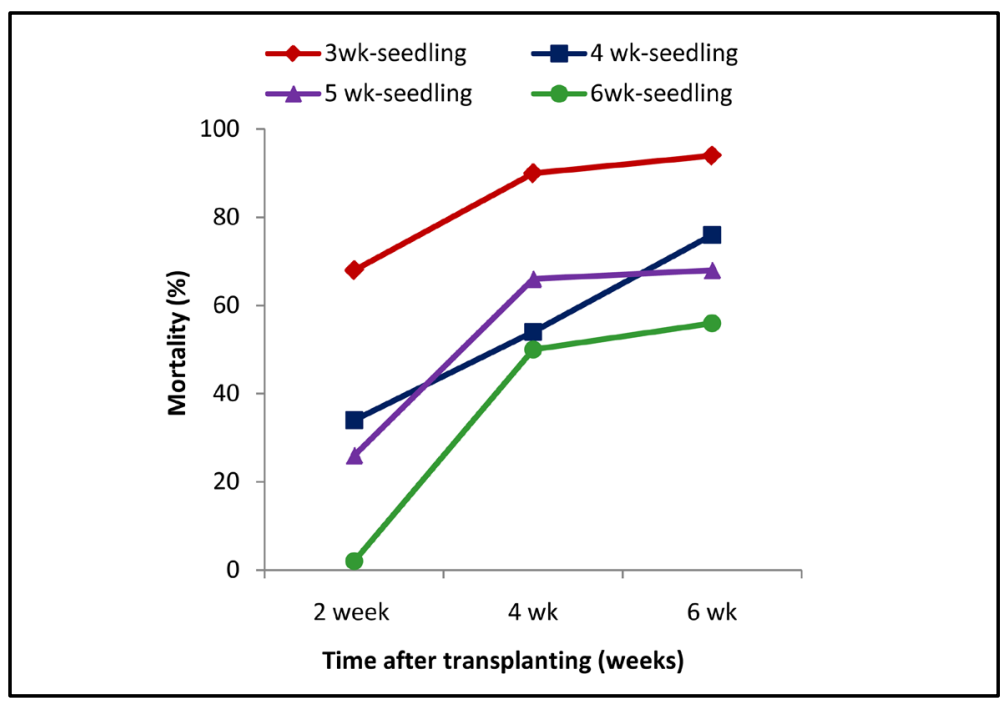

Figure 3. Disease incidence/extent of mortality (\%) after the transplanting of 3 - 6-week-old seedlings of tomato cv. Arka Vikas to Ralstonia sick soil in protrays over a span of 6 weeks.

transplanted to the above-mentioned pots displayed no disease incidence during the monitoring over the next 2 3 months although these pots had the additional inoculum from the previously knocked down seedlings. These 
plants came to flowering and fruiting, but none showed symptoms typical of pathogen infection till the end of 3 months.

The trial in earthen pots endorsed that the seedling age had a clear effect on the time taken for disease development. Within a month, $80 \%$ of the 3 -week-old seedlings and $60 \%$ of the 4 -week-old seedlings succumbed while 5 and 6 weeks old seedlings showed 60 and $80 \%$ survival, respectively. By the end of 4 months, $40 \%$ of the plants from the 6 weeks seedlings and $20 \%$ of the 5 weeks seedlings showed survival while 3 and 4 weeks seedling sets displayed $100 \%$ mortality.

\section{Discussion}

The present investigations were initiated based on the variable results on the extent of disease incidence during the protray screenings against Ralstonia in tomato at seedling stage and the preliminary indication that the percent morality in older seedlings was relatively less. The observations during the course of this study have confirmed that the seedlings age played a significant influence in governing the vulnerability of otherwise highly susceptible tomato genotype 'Arka Vikas' to the pathogen [7]. The influence was reflected in the responses to the pathogen both in challenge at the nursery stage in the protrays as well as at the time of transplanting to the field sick soil. The extent of disease incidence appeared to be influenced by the prevailing temperature with relatively less disease incidence during cooler months (Thomas, unpublished data). However, the pattern that younger seedlings were more susceptible remained irrespective of the season of trial. The experiments described in this report were conducted during the summer-autumn months when the day temperatures were in the 25 $35^{\circ} \mathrm{C}$ range. Temperature is known to be a factor influencing the response of tomato to Ralstonia [1] [11].

The observations in this study have two different ramifications. On one part, the variable response of the seedlings of different age groups to the challenge inoculation explains the variations in the extent of disease incidence during the course of seedling-stage screenings against this pathogen. In the point of view of culling the susceptible seedlings, two-week-old seedling stage formed the best for the maximum knock down effect such as in a disease resistance breeding program facilitating the discrimination between susceptible and resistant genotypes [7]. This was also advantageous as the results of the screening trials would become available before undertaking the field transplanting of the crop. On the other part, older seedlings appeared better suited towards disease management programs by minimizing the disease incidence under the field conditions.

Tomato is essentially a transplanted crop and root injury is unavoidable at transplanting, but could be minimized when the seedlings raised in protrays are transplanted to the field with the intact ball of cocopeat. It was not quite clear what factors in the older seedlings contributed to their higher levels of tolerance to the pathogen. Ralstonia being a root-invader, root growth was considered as a prime factor governing the entry/colonization by the pathogen. With the advancement in seedling age, the root growth showed a significant increase besides a significant improvement in overall seedling vigor. Although more root area/volume was available for pathogen entry/colonization with increase in seedling age, the susceptibility to $R$. solanacearum appeared in the reverse order, possibly because of root tissues turning hardier as the seedlings grew older. Seedlings raised in portray with cocopeat are normally transplanted at 3 - 3.5 weeks stage. Maintaining the seedlings for longer duration in protrays is considered to be not ideal. The observations here, however, suggest that keeping the seedlings in the protrays for longer duration could prove advantageous towards disease management in the field. In 5 - 6 weeks old seedlings, the roots appeared pot bound. However, following transplanting, they showed good establishment and plant stand.

\section{Conclusion}

The seedling age in protrays and at transplanting were found to have significant influences on the susceptibility of tomato to the wilt pathogen, $R$. solanacearum. Two-week-old seedlings showed the maximum susceptibility and formed the best stage towards knocking down susceptible seedlings such as in a screening programme. On the other hand, delaying transplanting to 5 - 6 weeks may help in reducing the vulnerability of seedlings to Ralstonia. Seedling age should be considered as an influencing factor while formulating disease management strategies.

\section{Acknowledgements}

The study was funded by the ICAR-AMAAS Net-work project on "Endophytic Microorganisms in Horticultural 
Crops" and the Institute Project 9.3.2 "Use of Endophytic Bacteria for Alleviating Ralstonia Wilt in Tomato". The publication bears IIHR contribution No. 33/2014.

\section{References}

[1] Hayward, A.C. (1991) Biology and Epidemiology of Bacterial Wilt Caused by Pseudomonas solanacearum. Annual Review of Phytopathology, 29, 65-87. http://dx.doi.org/10.1146/annurev.py.29.090191.000433

[2] Genin, S. and Denny, T.P. (2012) Pathogenomics of the Ralstonia solanacearum Species Complex. Annual Review of Phytopathology, 50, 67-89. http://dx.doi.org/10.1146/annurev-phyto-081211-173000

[3] Jyothi, H.K., Santhosha H.M. and Basamma (2012) Recent Advances in Breeding for Bacterial Wilt (Ralstonia solanacearum) Resistance in Tomato-Review. Current Biotica, 6, 370-398.

[4] Ji, P., Momol, M.T., Rich, J.R., Olson, S.M. and Jones, J.B. (2007) Development of an Integrated Approach for Managing Bacterial Wilt and Root-Knot on Tomato under Field Conditions. Plant Disease, 91, 1321-1326. http://dx.doi.org/10.1094/PDIS-91-10-1321

[5] Vanitha, S.C., Niranjana, S.R., Mortensen, C. N. and Umesha, S. (2009) Bacterial Wilt of Tomato in Karnataka and Its Management by Pseudomonas fluorescens. BioControl, 54, 685-695. http://dx.doi.org/10.1007/s10526-009-9217-x

[6] Ramesh, R. and Phadke, G.S. (2012) Rhizosphere and Endophytic Bacteria for the Suppression of Eggplant Wilt Caused by Ralstonia solanacearum. Crop Protection, 37, 35-41. http://dx.doi.org/10.1016/j.cropro.2012.02.008

[7] Thomas, P., Sadashiva, A.T., Upreti, R. and Mujawar, M.M. (2014) Direct Delivery of Inoculum to Shoot Tissue Interferes with Genotypic Resistance to Ralstonia solanacearum in Tomato Seedlings. Journal of Phytopathology, In Press.

[8] Kelman, A. (1954) The Relationship of Pathogenicity of Pseudomonas solanacearum to Colony Appearance in a Tetrazolium Medium. Phytopathology, 44, 693-695.

[9] Elphinstone, J.G., Hennessey, J., Wilson, J.K. and Stead, D.E. (1996) Sensitivity of Different Methods for the Detection of Ralstonia solanacearum in Potato Tuber Extracts. EPPO Bulletin, 26, 663-678. http://dx.doi.org/10.1111/j.1365-2338.1996.tb01511.x

[10] Thomas, P., Mujawar, M.M., Sekhar, A.C. and Upreti, R. (2014) Physical Impaction Injury Effects on Bacterial Cells during Spread-Plating Influenced by Cell Characteristics of the Organisms. Journal of Applied Microbiology, 116, 911-922. http://dx.doi.org/10.1111/jam.12412

[11] Mew, T.W. and Ho, W.C. (1977) Effect of Soil Temperature on Resistance of Tomato Cultivars to Bacterial Wilt. Phytopathology, 67, 909-911. http://dx.doi.org/10.1094/Phyto-67-909 